\title{
ANALISIS FAKTOR-FAKTOR YANG MEMPENGARUHI KEPUASAN KONSUMEN PADA LESEHAN ALDAN PERUMNAS CATURTUNGGAL DEPOK SLEMAN YOGYAKARTA
}

\section{Analysis of Factors that Influence Customer Satisfaction in Lesehan Aldan Restaurant Perumnas Caturtunggal Depok Sleman Yogyakarta}

\author{
Happy Bornyarso, Budiarto, Agus Santosa \\ Program Studi Agribisnis Jurusan Agribisnis Fakultas Pertanian \\ Universitas Pembangunan Nasional Veteran Yogyakarta \\ Jl. SWK 104 (Lingkar Utara) Condong Catur Yogyakarta Indonesia 55283 \\ *email korespondensi: hbornyarso@gmail.com
}

Diterima tanggal : 5 September 2020 ; Disetujui tanggal : 7 September 2020

\begin{abstract}
ABSTRAK
This research aimed to (1) analyze the effect of product quality, service quality, and price on customer satisfaction on "Lesehan Aldan" restaurant, (2) analyze the level of customer satisfaction on "Lesehan Aldan" restaurant. This research uses the basic method of descriptive. The implementation method uses a case study. The taking respondents' method uses accidental sampling, with total sample 40 respondents. The types of data used are primary data and secondary data. Data analysis techniques to analyze the effect of product quality, service quality, and price on customer satisfaction at "Lesehan Aldan" restaurant use multiple linear regression and techniques to analyze the level of customer satisfaction at "Lesehan Aldan" restaurant use Importance Performance Analysis (IPA). The results obtained show, (1) Product quality and service quality affect customer satisfaction, while price does not affect customer satisfaction at "Lesehan Aldan" restaurant (2) The level of customer satisfaction at "Lesehan Aldan" restaurant shows that consumers are dissatisfied based on the suitability between interests and performance on "Lesehan Aldan" restaurant. "Lesehan Aldan" restaurant is advised to maintain performance in the form of the cleanliness of the location, good service from the beginning to the end, serving accuracy, serving speed, and employee friendliness, as well as improving performance in the form of product flavor, taste consistency, and product nutritional content to increase customer satisfaction.
\end{abstract}

Keywords: customer satisfaction, price, product quality, service quality 


\begin{abstract}
ABSTRAK
Penelitian ini bertujuan (1) Menganalisis pengaruh antara kualitas produk, kualitas pelayanan, dan harga terhadap kepuasan konsumen pada Lesehan Aldan, (2) Menganalisis tingkat kepuasan konsumen pada Lesehan Aldan. Penelitian ini menggunakan metode dasar penelitian deskriptif. Metode pelaksanaan menggunakan metode studi kasus. Metode pengambilan responden menggunakan teknik sampling insidental, dengan jumlah sampel sebanyak 40 responden. Macam data yang digunakan berupa data primer dan data sekunder. Teknik analisis data untuk menganalisis pengaruh antara kualitas produk, kualitas pelayanan, dan harga terhadap kepuasan konsumen pada Lesehan Aldan menggunakan regresi linier berganda dan teknik untuk menganalisis tingkat kepuasan konsumen pada Lesehan Aldan menggunakan Importance Performance Analysis (IPA). Hasil yang diperoleh menunjukkan, (1) Kualitas produk dan kualitas pelayanan berpengaruh terhadap kepuasan konsumen, sedangkan harga tidak berpengaruh terhadap kepuasan konsumen pada Lesehan Aldan (2) Tingkat kepuasan konsumen pada Lesehan Aldan menunjukkan konsumen merasa tidak puas berdasarkan kesesuaian antara kepentingan dan kinerja pada Lesehan Aldan. Lesehan Aldan disarankan mempertahankan kinerja berupa kebersihan lokasi, pelayanan baik dari awal-akhir, ketepatan penyajian, kecepatan penyajian, dan keramahan karyawan, serta memperbaiki kinerja berupa citarasa produk, konsistensi rasa, dan kandungan gizi produk untuk dapat meningkatkan kepuasan konsumen.
\end{abstract}

Kata kunci: kualitas produk, kualitas pelayanan, harga, kepuasan konsumen

\title{
PENDAHULUAN
}

Di era modern saat ini, pertumbuhan industri ekonomi kreatif di Indonesia dapat dikatakan sangat potensial. Hal tersebut menunjukkan bahwa terdapat persaingan sehat di setiap subsektor untuk terus berinovasi dan mengembangkan usahanya agar dapat berjalan seiring dengan perkembangan zaman. Persentase kontribusi Produk Domestik Bruto (PDB) ekonomi kreatif di Indonesia didominasi oleh 3 subsektor yaitu subsektor kuliner, fashion, dan kriya dengan persentase secara berurutan memiliki nilai sebesar $41,4 \%, 18,01 \%$ dan $15,4 \%$. Hal tersebut menunjukkan pertumbuhan ekonomi kreatif pada subsektor kuliner saat ini menarik perhatian lebih masyarakat untuk berwirausaha pada bidang tersebut. Sedangkan untuk data statistik persentase Produk Domestik Regional Bruto (PDRB) berdasarkan oleh lima provinsi di Indonesia, terbesar secara berurutan dari tahun sebelumnya ditempati wilayah Yogyakarta dengan peningkatan sebesar 
10.29\%, Bali sebesar 5.4\%, Jawa Barat sebesar 5.19\%, Jawa Timur sebesar 3.71\%, sedangkan penurunan dialami Sumatra Utara sebesar 1.88\%.

Kedua data statistik tersebut menjadi relevan karena saat ini dapat dengan mudah kita jumpai bisnis kuliner bertebaran di wilayah Yogyakarta, dengan berbagai merk yang terus berkembang tentunya menyebabkan persaingan bisnis sejenis menjadi lebih ketat. Menurut Hardyasar (2017) kualitas produk merupakan senjata strategis yang potensial untuk mengalahkan pesaing, sehingga hanya perusahaan dengan mempunyai kualitas produk yang paling baik akan tumbuh dengan pesat dan dalam jangka waktu yang panjang perusahaan tersebut akan berhasil dari perusahaan yang lain.

Di dunia kuliner Yogyakarta, ada nama rumah makan yang mudah kita jumpai disekitar kita yaitu Lesehan Aldan. Lesehan Aldan merupakan rumah makan yang didirikan pada tahun 2005 oleh Suliyanto di Yogyakarta. Lesehan Aldan berkembang pada tahun 2013 hingga saat ini mencapai jumlah total 41 cabang. Salah satunya berlokasi di Jalan Perumnas, Kelurahan Caturtunggal, Kecamatan Depok, Kabupaten Sleman, Provinsi Daerah Istimewa Yogyakarta yang didirikan pada tahun 2014. Lesehan Aldan ini dipimpin oleh Arif Nurohman.

Lesehan Aldan memiliki keunggulan kualitas produk dari segi variasi produk dan kualitas pelayanan yang diberikan kepada konsumen. Menurut Kotler (2002), kualitas produk adalah karakteristik produk atau jasa yang bergantung pada kemampuannya untuk memuaskan kebutuhan pelanggan yang dinyatakan atau diimplikasikan, sedangkan kualitas pelayanan dapat diketahui dengan cara membandingkan persepsi para konsumen atas pelayanan yang nyata-nyata mereka terima/peroleh dengan pelayanan yang sesungguhnya mereka harapkan/inginkan terhadap atribut-atribut pelayanan suatu perusahaan (Tjiptono, 2001). Faktor lain yang dapat mempengaruhi suatu usaha adalah harga, merupakan satu-satunya unsur bauran pemasaran yang memberikan pemasukan/pendapatan bagi perusahaan (Guntur, 2010). Konsumen yang telah melakukan konsumsi akan melakukan evaluasi apakah produk/jasa yang dikonsumsi tersebut sesuai dengan apa yang diharapkan/ tidak. Apabila perceived quality sesuai bahkan melebihi expected quality maka timbul kepuasan dalam diri konsumen (Gunawan, 2017). 
Pada tahun 2019 Lesehan Aldan menunjukkan adanya fluktuasi pendapatan, menurut manajer warung kondisi ini tergolong sepi pengunjung karena Lesehan Aldan mempunyai indikator target pendapatan yang tidak tercapai. Pihak manajemen rumah makan tentunya hingga saat ini berusaha untuk memperbaiki kekurangan yang ada demi memberikan kepuasan konsumennya. Berdasarkan uraian latar belakang tersebut maka penelitian ini bertujuan untuk menganalisis pengaruh antara kualitas produk, kualitas pelayanan, dan harga terhadap kepuasan konsumen pada Lesehan Aldan, dan Menganalisis tingkat kepuasan konsumen pada Lesehan Aldan.

\section{METODE PENELITIAN}

Metode penelitian yang digunakan adalah metode deskriptif. bertujuan untuk membuat deskripsi, gambaran atau lukisan secara sistematis, faktual dan akurat mengenai fakta-fakta, sifat-sifat serta hubungan antar fenomena yang diselidiki (Nazir, 2011). Dalam penelitian ini, menunjukkan fenomena konsumen merasa tidak puas ditandai dengan adanya keluhan/ pengaduan yang diberikan kepada Lesehan Aldan terkait kualitas produk, kualitas pelayanan, dan harga.

Metode penelitian yang digunakan adalah metode studi kasus, bertujuan untuk memberikan gambaran secara mendetail tentang latar belakang, sifat-sifat serta karakter-karakter yang khas dari kasus, ataupun status dari individu, yang kemudian dari sifat-sifat khas diatas akan dijadikan suatu hal yang bersifat umum (Nazir, 2011). Dalam penelitian ini, karakteristik khas yang membedakan dengan restoran sejenis lainnya, adanya menu paket couple, dan variasi sambal mencapai 15 jenis, dan Lesehan Aldan Perumnas mempunyai area meja Outdoor.

Metode pengambilan responden yang digunakan adalah Non Probability Sampling yang merupakan teknik pengambilan sampel yang tidak memberi peluang/ kesempatan yang sama bagi setiap unsur atau anggota populasi untuk dipilih menjadi sampel. Pendekatan yang digunakan adalah Sampling Insidental yaitu teknik penentuan sampel berdasarkan kebetulan, yaitu siapa saja yang secara kebetulan/ insidental bertemu dengan peneliti dapat digunakan sebagai sampel, bila dipandang orang yang kebetulan ditemui itu cocok sebagai sumber data. 
Dalam penelitian ini, menggunakan sampel sebanyak 40 responden, dengan pengambilan sampel disesuaikan teori Roscoe.

Macam data yang digunakan adalah data primer, merupakan data survei, pengamatan, atau eksperimen yang dikumpulkan untuk memecahkan masalah tertentu yang sedang diselidiki meliputi keadaan umum Lesehan Aldan dan tanggapan responden penyebaran kuesioner, dan data sekunder, mencakup informasi yang telah dikumpulkan dan hanya mungkin relevan dengan permasalahan yang ada meliputi sejarah Lesehan Aldan. Sedangkan sumber data diperoleh dari manajer Lesehan Aldan Perumnas, responden Lesehan Aldan Perumnas, pustaka, dan internet.

Metode pengumpulan data dilakukan dengan beberapa cara diantaranya melalui: (1) kuesioner, yaitu teknik pengumpulan data dengan cara mengirimkan suatu daftar pertanyaan kepada responden untuk diisi, (2) observasi, merupakan pengamatan dan pencatatan sesuatu obyek meliputi keadaan umum pada Lesehan Aldan, (3) interview, merupakan proses tanya jawab lisan, dengan dua orang atau lebih berhadapan langsung secara fisik dengan manajer Lesehan Aldan Perumnas.

Menganalisis Pengaruh Antara Kualitas Produk, Kualitas Pelayanan, Dan

\section{Harga Terhadap Kepuasan Konsumen Pada Lesehan Aldan}

Untuk menganalisis tujuan pertama digunakan analisis regresi linier berganda. Teknik regresi linier berganda digunakan untuk mengetahui ada tidaknya pengaruh signifikan dua/ lebih variabel bebas terhadap variabel terikat (Mona, 2015). Rumus regresi linier berganda dapat dilihat pada Persamaan (1).

$\mathrm{Y}=\mathrm{a}+\mathrm{b}_{1} \mathrm{x}_{1}+\mathrm{b}_{2} \mathrm{x}_{2}+\mathrm{b}_{3} \mathrm{x}_{3}+\mathrm{e}$

Keterangan :

$\mathrm{Y} \quad=$ Kepuasan Konsumen

a $\quad=$ Konstanta (nilai $Y^{\prime}$ apabila $\mathrm{X}_{1}, \mathrm{X}_{2} \ldots . . \mathrm{X}_{\mathrm{n}}=0$ )

$\mathrm{b}_{1} \quad=$ Koefisien regresi kualitas produk

$\mathrm{x}_{1} \quad=$ Kualitas produk

$\mathrm{b}_{2} \quad=$ Koefisien regresi kualitas pelayanan

$\mathrm{x}_{2} \quad=$ Kualitas pelayanan

$\mathrm{b}_{3} \quad=$ Koefisien regresi harga

$\mathrm{x}_{3} \quad=$ Harga

e $\quad=$ Standar error 


\section{Menganalisis Tingkat Kepuasan Konsumen Pada Lesehan Aldan}

Untuk menganalisis tujuan kedua digunakan Importance Performance Analysis (IPA) yang merupakan teknik analisis untuk mengidentifikasi faktorfaktor kinerja penting yang ditunjukkan oleh organisasi dalam memenuhi kepuasan konsumen, dengan cara membandingkan antara harapan konsumen dengan kinerja yang dilakukannya. Apabila tingkat harapannya lebih tinggi daripada kinerja perusahaan berarti konsumen tersebut belum mencapai kepuasan, begitu pula sebaliknya. Dengan menggunakan metode IPA, diketahui informasi berkaitan dengan atribut atribut pelayanan yang menurut konsumen sangat mempengaruhi kepuasan dan loyalitas mereka, dan faktor-faktor pelayanan yang menurut konsumen perlu ditingkatkan karena kondisi saat ini belum memuaskan (Winanda, 2016). Dalam penelitian ini terdapat dua sumbu yang diwakilkan oleh huruf $\mathrm{Y}$ dan $\mathrm{X}$, dimana $\mathrm{X}$ merupakan tingkat kinerja, sedangkan $\mathrm{Y}$ merupakan tingkat kepentingan. Adapun rumusnya dapat dilihat pada Persamaan (2).

$\mathrm{TKi}=\frac{\mathrm{Xi}}{\mathrm{Yi}} \times 100 \%$

Keterangan :

TKi $\quad=$ Tingkat kesesuaian responden

$\mathrm{Xi} \quad=$ Skor penilaian kinerja rumah makan

$\mathrm{Yi} \quad=$ Skor penilaian kepentingan konsumen

Sumbu mendatar (X) akan diisi oleh skor tingkat kinerja, sedangkan sumbu tegak (Y) akan diisi oleh skor tingkat kepentingan. Setelah itu menghitung total tingkat kesesuaian responden, dengan menggunakan rumus yang dapat dilihat pada Persamaan (3).

TKitotal $=\frac{\sum \mathrm{Xi}}{\sum \mathrm{Yi}} \times 100 \%$

Keterangan :

TKitotal $=$ Total tingkat kesesuaian responden

$\sum \mathrm{Xi} \quad=$ Total skor penilaian kinerja rumah makan

$\sum \mathrm{Yi}=$ Total skor penilaian kepentingan konsumen 
Diagram kartesius digunakan untuk mengetahui indikator atribut yang memuaskan atau tidak memuaskan konsumen. Rumus yang digunakan dapat dilihat pada Persamaan (4).

$\overline{\overline{\mathrm{X}}}=\frac{\sum \overline{\mathrm{X}} \mathrm{i}}{\mathrm{k}} \quad$ dan $\quad \overline{\overline{\mathrm{Y}}}=\frac{\sum \overline{\mathrm{Y}} \mathrm{i}}{\mathrm{k}}$

Keterangan :

$\overline{\overline{\mathrm{X}}}$

$\overline{\bar{Y}}$

K

$=$ Rata-rata dari skor rata-rata tingkat kinerja

$=$ Rata-rata dari skor rata-rata tingkat kepentingan

$=$ Jumlah atribut pertanyaan

Selanjutnya dijabarkan ke beberapa bagian dalam diagram kartesius beserta penjelasannya seperti pada Gambar 1. Diagram Kartesius berikut:

\begin{tabular}{|c|c|c|}
\hline \multirow{2}{*}{$\begin{array}{r}\overline{\overline{\mathrm{Y}}} \\
\text { Kepentingan }\end{array}$} & $\begin{array}{l}\text { Kuadran I } \\
\text { Prioritas Pertama }\end{array}$ & $\begin{array}{l}\text { Kuadran II } \\
\text { Pertahankan Prestasi }\end{array}$ \\
\hline & $\begin{array}{l}\text { Kuadran III } \\
\text { Prioritas Rendah }\end{array}$ & $\begin{array}{l}\text { Kuadran IV } \\
\text { Berlebihan }\end{array}$ \\
\hline
\end{tabular}

Gambar 1. Diagram Kartesius

Sumber: Anggraini (2015)

Kuadran (I) Menunjukkan faktor atau atribut yang dianggap mempengaruhi kepuasan konsumen, namun manajemen belum melaksanakannya sesuai dengan keinginan konsumen sehingga mengecewakan/tidak puas. Kuadran (II) Menunjukkan unsur jasa pokok yang telah berhasil dilaksanakan. Untuk itu wajib dipertahankannya. Dianggap sangat penting dan sangat memuaskan. Kuadran (III) Menunjukkan beberapa faktor yang kurang penting pengaruhnya bagi konsumen. Dianggap kurang penting dan kurang memuaskan. Kuadran (IV) Menunjukkan faktor yang konsumen berekspektasi rendah namun pelaksanaan kinerja atribut dinilai sangat baik. Dianggap kurang penting tetapi memuaskan. 


\section{HASIL DAN PEMBAHASAN}

\section{Pengaruh Antara Kualitas Produk, Kualitas Pelayanan, dan Harga terhadap Kepuasan Konsumen pada Lesehan Aldan}

Untuk mengetahui pengaruh kualitas produk, kualitas pelayanan, dan harga terhadap kepuasan konsumen di Lesehan Aldan digunakan analisis regresi linear berganda. Data penelitian yang di analisis menggunakan bantuan program SPSS. Faktor-faktor yang berpengaruh terhadap kepuasan konsumen di Lesehan Aldan dapat dilihat pada Tabel. 1.

Tabel 1. Hasil Analisis Regresi Linier Berganda

\begin{tabular}{lcc}
\hline \multicolumn{1}{c}{ Variabel } & Koefisien Regresi & Sig. \\
\hline Konstanta & $-1,950$ & 0,070 \\
Kualitas Produk (X1) & $0,217^{*}$ & 0,000 \\
Kualitas Pelayanan (X2) & $0,257^{*}$ & 0,000 \\
Harga (X3) & $0,164^{*}$ & 0,053 \\
Variabel Terikat (Y) : Kepuasan Konsumen & & \\
Adjusted R Square & & 0,678 \\
Sig. F & & 0,000 \\
\hline
\end{tabular}

Sumber: Data primer diolah (2020)

Keterangan $(*)$ : Signifikan $\alpha$ pada $=5 \%=0,05$

Berdasarkan Tabel 1., dapat dituliskan rumus persamaan hasil analisis regresi linear berganda pada Persamaan (5).

$\mathrm{Y}=-1,950+0,217 \mathrm{X} 1+0,257 \mathrm{X} 2+0,164 \mathrm{X} 3+\mathrm{e}$

Nilai Koefisien determinasi (Adjusted $R^{2}$ ) sebesar 0,678, yang artinya variabel bebas kualitas produk, kualitas pelayanan, dan harga berpengaruh sebesar $67,8 \%$ terhadap variabel terikat kepuasan konsumen, sedangkan sisanya sebesar $32.2 \%$ dipengaruhi oleh variabel lain yang tidak diteliti. Dari pengujian berdasarkan uji F, diperoleh nilai Sig. F sebesar 0,000<0,05, maka disimpulkan kualitas produk, kualitas pelayanan, dan harga secara bersama-sama berpengaruh terhadap kepuasan konsumen pada Lesehan Aldan.

Dari pengujian berdasarkan uji t, diperoleh hasil variabel Kualitas Produk (X1) memiliki nilai Sig. 0,000 $<0,05$, dan nilai thitung 4,295 $>t_{\text {tabel }} 2,028$, yang artinya Kualitas Produk (X1) berpengaruh secara parsial terhadap Kepuasan Konsumen (Y), Hal ini didukung penelitian Montung, (2015) bahwa kualitas 
produk berpengaruh terhadap kepuasan konsumen. Variabel Kualitas Pelayanan (X2) memiliki nilai Sig. 0,000<0,05, dan nilai $t_{\text {hitung }} 5,222>t_{\text {tabel }} 2,028$, yang artinya Kualitas Pelayanan (X2) berpengaruh secara parsial terhadap Kepuasan Konsumen (Y) Hal ini didukung penelitian Tombeng, (2015) bahwa kualitas pelayanan berpengaruh terhadap kepuasan konsumen. Variabel Harga (X3) memiliki nilai Sig. $0,053>0,05$, dan nilai $t_{\text {hitung }} 2,000<t_{\text {tabel }} 2,028$, yang artinya Harga (X3) tidak berpengaruh secara parsial terhadap Kepuasan Konsumen (Y).

\section{Tingkat Kepuasan Konsumen pada Lesehan Aldan}

Dalam pengujian ini, menggunakan Importance Performance Analysis (IPA) untuk menganalisis total tingkat kesesuaian antara kepentingan dan kinerja pada variabel kualitas produk, kualitas pelayanan, dan harga pada Lesehan Aldan. Untuk nilai Mean kinerja dan Mean kepentingan dapat dilihat pada Tabel. 2.

Tabel 2. Total Tingkat Kesesuaian Kepentingan dan Kinerja

\begin{tabular}{lcccc}
\hline \multicolumn{1}{c}{ Indikator Pertanyaan } & \multicolumn{2}{c}{ Jumlah } & \multicolumn{2}{c}{ Rata-Rata } \\
& Kinerja & Kepentingan & Kinerja & Kepentingan \\
\hline $\begin{array}{l}\text { Produk yang disajikan memiliki } \\
\text { citarasa yang enak }\end{array}$ & 147 & 185 & 3.68 & 4.63 \\
$\begin{array}{l}\text { Cita rasa produk yang disajikan } \\
\text { tidak pernah berubah-ubah }\end{array}$ & 149 & 181 & 3.73 & 4.53 \\
$\begin{array}{l}\text { Penyajikan produk memiliki } \\
\text { tekstur yang baik }\end{array}$ & 136 & 161 & 3.40 & 4.03 \\
$\begin{array}{l}\text { Produk Lesehan Aldan memiliki } \\
\text { kandungan gizi yang tinggi }\end{array}$ & 132 & 174 & 3.30 & 4.35 \\
$\begin{array}{l}\text { Penyajian produk dengan } \\
\text { tampilan yang rapi dan menarik }\end{array}$ & 144 & 162 & 3.60 & 4.05 \\
$\begin{array}{l}\text { Produk Lesehan Aldan memiliki } \\
\text { aroma yang sedap }\end{array}$ & 145 & 156 & 3.63 & 3.90 \\
$\begin{array}{l}\text { Produk yang disajikan dalam } \\
\text { kondisi suhu yang tepat }\end{array}$ & 148 & 162 & 3.70 & 4.05 \\
$\begin{array}{l}\text { Kebersihan meja makan terjaga } \\
\text { dengan baik }\end{array}$ & 158 & 178 & 3.95 & 4.45 \\
$\begin{array}{l}\text { Pelayan melayani konsumen } \\
\text { dengan baik dari awal hingga } \\
\text { akhir }\end{array}$ & 156 & 185 & 3.90 & 4.63 \\
$\begin{array}{l}\text { Pelayan menyajikan pesanan } \\
\text { konsumen dengan tepat }\end{array}$ & 174 & 181 & 4.35 & 4.53 \\
$\begin{array}{l}\text { Konsumen tidak perlu } \\
\text { menunggu lama sejak pesanan } \\
\text { dibuat }\end{array}$ & 169 & 176 & 4.23 & 4.40 \\
& & & &
\end{tabular}


Jurnal Dinamika Sosisal Ekonomi, 21 (2) : 137-149

Lanjutan Tabel 2. Total Tingkat Kesesuaian Kepentingan dan Kinerja

\begin{tabular}{|c|c|c|c|c|}
\hline \multirow{2}{*}{ Indikator Pertanyaan } & \multicolumn{2}{|c|}{ Jumlah } & \multicolumn{2}{|c|}{ Rata-Rata } \\
\hline & Kinerja & Kepentingan & Kinerja & Kepentingan \\
\hline $\begin{array}{l}\text { Pelayan ramah dan sopan kepada } \\
\text { konsumen }\end{array}$ & 180 & 186 & 4.50 & 4.65 \\
\hline $\begin{array}{l}\text { Pelayan selalu ada setiap } \\
\text { dibutuhkan konsumen }\end{array}$ & 179 & 145 & 4.48 & 3.63 \\
\hline $\begin{array}{l}\text { Harga yang ditawarkan } \\
\text { terjangkau oleh konsumen }\end{array}$ & 153 & 163 & 3.83 & 4.08 \\
\hline $\begin{array}{l}\text { Harga produk yang ditawarkan } \\
\text { lebih rendah dari pesaing yang } \\
\text { lain }\end{array}$ & 124 & 153 & 3.10 & 3.83 \\
\hline $\begin{array}{l}\text { Harga yang ditawarkan sesuai } \\
\text { dengan kualitas produk }\end{array}$ & 152 & 182 & 3.80 & 4.55 \\
\hline $\begin{array}{l}\text { Harga yang ditawarkan sesuai } \\
\text { dengan manfaat yang diterima } \\
\text { konsumen }\end{array}$ & 144 & 162 & 3.60 & 4.05 \\
\hline JUMLAH & 2590 & 2892 & 64.76 & 72.30 \\
\hline
\end{tabular}

Sumber: Data primer diolah (2020)

Total tingkat kesesuaian antara kepentingan dan kinerja pada variabel kualitas produk, kualitas pelayanan, dan harga dapat dilihat pada Persamaan (6).

TKitotal $=\frac{2590}{2892} \times 100 \%$

TKitotal $=89,55 \%$

Berdasarkan Tabel 2. diperoleh hasil yang menunjukkan total tingkat kesesuaian sebesar $89.55 \%$, dan nilai total Mean kinerja lebih kecil daripada Mean kepentingan sebesar 64.76<72.30. Dari pengujian hipotesis kedua, maka disimpulkan konsumen merasa tidak puas berdasarkan kesesuaian antara kepentingan dan kinerja di Lesehan Aldan.

\section{Diagram Kartesius}

Berdasarkan diagram kartesius, indikator kualitas produk, kualitas pelayanan, dan harga yang dianalisis tersebar menjadi empat bagian yaitu kuadran I (prioritas utama), kuadran II (pertahankan prestasi), kuadran III (prioritas rendah) dan kuadran IV (berlebihan). Hal ini dapat dilihat pada Gambar. 2. 


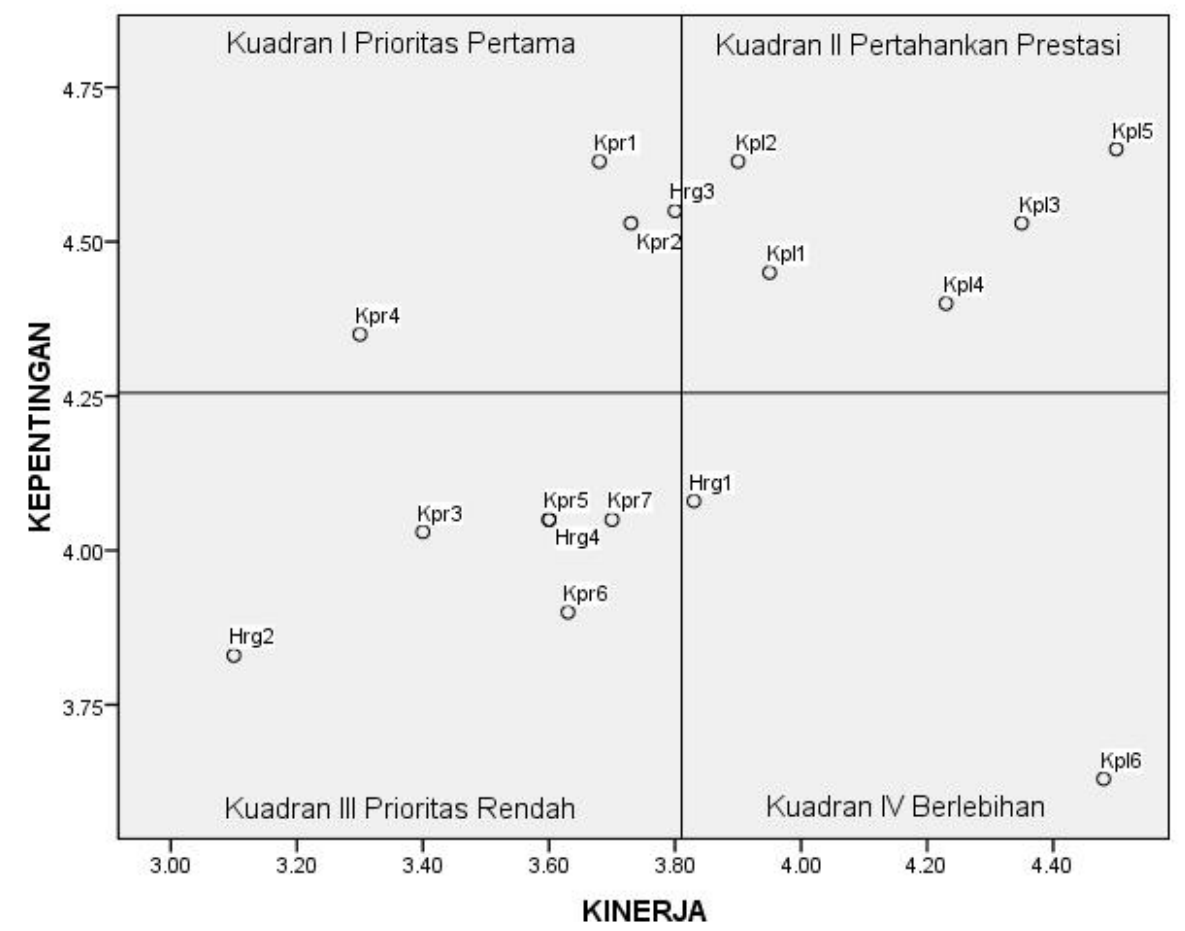

Gambar 2. Diagram Kartesius

Sumber: Data primer diolah (2020)

Untuk keterangan atribut Diagram Kartesius, dapat dilihat pada Tabel 3.

Tabel 3. Atribut Diagram Kartesius

\begin{tabular}{cl}
\hline Atribut & \multicolumn{1}{c}{ Keterangan } \\
\hline Kpr1 & Produk yang disajikan memiliki citarasa yang enak \\
Kpr2 & Cita rasa produk yang disajikan tidak pernah berubah-ubah \\
Kpr4 & Produk Lesehan Aldan memiliki kandungan gizi yang tinggi \\
Hrg3 & Harga yang ditawarkan sesuai dengan kualitas produk \\
Kp11 & Kebersihan meja makan terjaga dengan baik \\
Kp12 & Pelayan melayani konsumen dengan baik dari awal hingga akhir \\
Kp13 & Pelayan menyajikan pesanan konsumen dengan tepat \\
Kp14 & Konsumen tidak perlu menunggu lama sejak pesanan dibuat \\
Kp15 & Pelayan ramah dan sopan kepada konsumen \\
Kpr3 & Penyajikan produk memiliki tekstur yang baik \\
Kpr5 & Penyajian produk dengan tampilan yang rapi dan menarik \\
Kpr6 & Produk Lesehan Aldan memiliki aroma yang sedap \\
Kpr7 & Produk yang disajikan dalam kondisi suhu yang tepat \\
Hrg2 & Harga produk yang ditawarkan lebih rendah dari pesaing yang lain \\
Hrg4 & Harga yang ditawarkan sesuai dengan manfaat yang diterima konsumen \\
Kp16 & Pelayan selalu ada setiap dibutuhkan konsumen \\
Hrg1 & Harga yang ditawarkan terjangkau oleh konsumen \\
\hline
\end{tabular}


Berdasarkan Gambar 2., Pada Kuadran I Prioritas Pertama terdapat 4 atribut, meliputi produk yang disajikan memiliki citarasa yang enak, cita rasa produk yang disajikan tidak pernah berubah-ubah, produk lesehan aldan memiliki kandungan gizi yang tinggi, harga yang ditawarkan sesuai dengan kualitas produk. Pada Kuadran II Pertahankan Prestasi terdapat 5 atribut, meliputi kebersihan meja makan terjaga dengan baik, pelayan melayani konsumen dengan baik dari awal hingga akhir, pelayan menyajikan pesanan konsumen dengan tepat, konsumen tidak perlu menunggu lama sejak pesanan dibuat, pelayan ramah dan sopan kepada konsumen. Pada Kuadran III Prioritas Rendah terdapat 6 atribut, meliputi penyajikan produk memiliki tekstur yang baik, penyajian produk dengan tampilan yang rapi dan menarik, produk lesehan aldan memiliki aroma yang sedap, produk yang disajikan dalam kondisi suhu yang tepat, harga produk yang ditawarkan lebih rendah dari pesaing yang lain, harga yang ditawarkan sesuai dengan manfaat yang diterima konsumen. Pada Kuadran IV Berlebihan terdapat 2 atribut, meliputi pelayan selalu ada setiap dibutuhkan konsumen, dan harga yang ditawarkan terjangkau oleh konsumen.

\section{KESIMPULAN DAN SARAN}

\section{Kesimpulan}

Kualitas produk dan kualitas pelayanan berpengaruh terhadap kepuasan konsumen, sedangkan harga tidak berpengaruh terhadap kepuasan konsumen pada Lesehan Aldan. Tingkat kepuasan konsumen pada Lesehan Aldan menunjukkan konsumen merasa tidak puas berdasarkan kesesuaian antara kepentingan dan kinerja pada Lesehan Aldan.

\section{Saran}

Lesehan Aldan disarankan meningkatkan kesigapan pelayan untuk menandai terlebih dahulu daftar menu produk yang habis sebelum menu diberikan kepada konsumen, sehingga konsumen tidak membuang waktu terlanjur memesan produk yang tidak tersedia. Lesehan Aldan disarankan mempertahankan kinerja atribut pada kuadran II diagram kartesius, seperti kebersihan lokasi, pelayanan baik dari awal-akhir, ketepatan penyajian, kecepatan penyajian, dan keramahan 
Bornyarso et.al. Analisis Faktor-Faktor Yang Mempengaruhi Kepuasan

karyawan, serta memperbaiki kinerja atribut pada kuadran I yang menjadi prioritas pertama, terlebih variabel yang mempengaruhi kepuasan seperti citarasa produk, konsistensi rasa, dan kandungan gizi produk.

\section{DAFTAR PUSTAKA}

Kotler, Philip. (2002). Manajemen Pemasaran di Indonesia, Analisis, Perencanaan, Implementasi dan Pengendalian. Jakarta: Salemba Empat.

Guntur, Effendi M. (2010). Transformasi Manajemen Pemasaran. Jakarta: Sagung Seto.

Anggraini, Lulu Dian, Deoranto P, Ikasari D.M. (2015). Analisis Persepsi Konsumen Menggunakan Metode Importance Performance Analysis dan Customer Satisfaction Index. Jurnal Industri, 4 (2). 74-81.

Gunawan, Ayumi Fitriani dan Priatna, Wahyu Budi. (2017). Tingkat Kepuasan Konsumen Terhadap Restoran Happy Cow Steak Bogor Jawa Barat. Jurnal Forum Agribisnis, 5 (2), 139-158.

Hardyasar, Arthurm Mandei J.R, Dumais J.N.K. (2017). Tingkat Kepuasan

Konsumen Restoran Pondok Hijau Kota Manado. Jurnal Agri-Sosio Ekonomi Unsrat, 13 (3). 157-172.

Mona, Margaretha G, Kekenusa J.S, Prang J.D. (2015). Penggunaan Regresi Linear Berganda untuk Menganalisis Pendapatan Petani Kelapa. Jurnal Ilmiah JdC. 4 (2), 197-203.

Montung, Pamela, Sepang J, Adare D. (2015). Pengaruh Kualitas Produk, Kualitas Layanan dan Persepsi Harga terhadap Kepuasan Pelanggandi Restoran Kawan Baru. Jurnal Berkala Ilmiah Efisiensi, 15 (5). 678-689.

Nazir, Mohammad. (2011). Metode Penelitian. Bogor: Ghalia Indonesia.

Tjiptono, Fandy. (2001). Strategi Pemasaran. Edisi Pertama. Yogyakarta: Andi Offset.

Tombeng, Brigitte, Roring F, Rumokoy F.S. (2015). Pengaruh Kualitas Pelayanan, Harga dan Kualitas Produk terhadap Kepuasan Konsumen pada Rumah Makan Raja Oci Manado. Jurnal EMBA,7 (1): 891-900.

Winanda, Ariani Putri dan Sriyanto. (2016). Analisis Kualitas Pelayanan Restoran Cepat Saji dengan Metode Servqual (Service Quality) dan Ipa (Importance Performance Analysis) (Studi Kasus Restoran Olive Fried Chicken). Industrial Engineering Online Journal, 5 (4): 1-6. 